CADERNOS GESTÃo PÚBLICA E CIDADANIA

\title{
PARCERIAS, NOVOS ARRANJOS INSTITUCIONAIS E POLÍTICAS PÚBLICAS LOCAIS
}

Marta Ferreira Santos Farah 


\section{A Autora}

\section{Marta Ferreira Santos Farah}

Doutora em Sociologia pela Universidade de São Paulo. Professora da EAESP da Fundação Getúlio Vargas de São Paulo, participou do processo de implantação do Programa Gestão Pública e Cidadania e é vice-coordenadora do Programa desde 1995.

* Este artigo foi publicado na Revista de Administração Pública - FARAH, Marta Ferreira Santos. Parcerias, novos arranjos institucionais e políticas públicas no nível local de governo. RAP - Revista de Administração Pública, v.35, n. 1, p. 119-145, jan./fev. 2001 


\section{Índice}

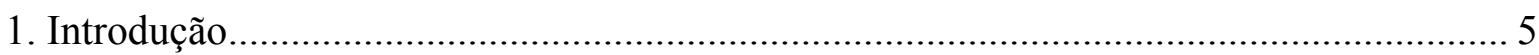

2. Características das políticas públicas até o início dos anos 80 ..................................... 6

3. A agenda da reforma das políticas sociais ......................................................... 10

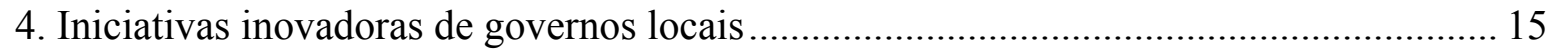

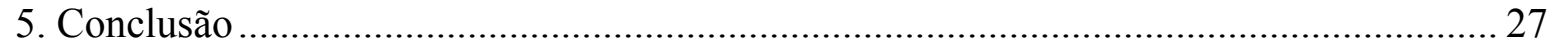

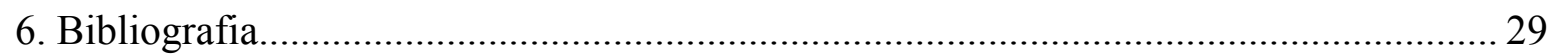




\section{Introdução}

Na passagem para o século XXI, a imagem que prevalece a respeito do Estado no Brasil é uma imagem negativa, influenciada pela perspectiva minimalista que se consolidou a partir da crise econômica e do próprio Estado que atingiu tanto os países centrais como os países em desenvolvimento a partir dos anos 70. Embora já esteja ocorrendo uma revisão do consenso anti-estatal nos países desenvolvidos e mesmo no âmbito das agências financeiras multilaterais que condicionam boa parte das políticas públicas nos países em desenvolvimento (EVANS, 1993, REZENDE, 1996, STIGLITZ, 1998 e IGLESIAS, 2000), no Brasil ainda é bastante difundido um clima de desconfiança com relação ao setor estatal que ultrapassa largamente o questionamento da capacidade do Estado de alavancar o desenvolvimento. $\mathrm{O}$ descrédito em relação ao Estado e à administração pública diz respeito à ação estatal, às diversas políticas públicas, e aos políticos de um modo geral. A ocorrência de práticas de cunho clientelista e marcadas pela corrupção após a democratização dos anos 80 e a maior visibilidade destes fenômenos, decorrente da própria democratização, articularam-se à onda minimalista de corte neoliberal que propõe a redução radical do Estado, contaminando a visão que os cidadãos têm da ação governamental e da administração pública em todas as esferas de governo. No limite, constrói-se no imaginário coletivo uma perspectiva de "ausência de perspectivas", segundo a qual não apenas o Estado é ineficiente por natureza como, na relação Estado-Sociedade no Brasil, tudo tem permanecido igual e nada mudará jamais, uma vez que os vícios desta relação são inerentes ao próprio Estado. Nesta perspectiva, o Estado não é passível de reforma, a não ser através de sua redução ao Estado mínimo.

A superação no Brasil do clima anti-estatal não deverá resultar apenas da influência de uma eventual revisão do consenso pró-mercado por parte dos países desenvolvidos e das agências multilaterais de financiamento (em que pese o impacto considerável desta influência), mas também da construção interna de uma nova imagem a respeito da ação estatal. A construção desta nova imagem supõe o reconhecimento de que o Estado é passível de reformas orientadas tanto para a superação de características críticas de sua atuação no período nacional-desenvolvimentista como para sua adequação aos desafios postos pela globalização, pela reestruturação produtiva e pelo processo - ainda inconcluso - de democratização. 
É possível identificar atualmente no país uma série de iniciativas promovidas sobretudo por governos locais que sugerem estar em curso um processo embrionário de reconstrução do Estado no Brasil, em que se destacam o estabelecimento de uma nova relação entre Estado e Sociedade e a redefiniç̧ão da esfera pública. Embora a importância crescente dos governos locais, não apenas no Brasil, possa ser vista como parte de um processo de "desmonte" do Estado central, consistente com a tese do Estado mínimo, certamente não se limita a isto. No Brasil, o movimento em curso na esfera local pode ser entendido como parte de um processo de reconstrução da esfera pública, orientado para a democratização da gestão e das políticas públicas no país, o qual tem na descentralização um de seus componentes centrais1.

O objetivo deste artigo é discutir os processos de transformação em curso na esfera local de governo, chamando a atenção para a ampliação do leque de atores envolvidos na formulação, na implementação e no controle das políticas públicas e para o estabelecimento de parcerias - entre Estado e sociedade e entre organizações do próprio Estado - para a provisão de serviços públicos e para a formulação e implementação de políticas.

A análise das iniciativas promovidas pelos governos locais ${ }^{2}$ será precedida de uma breve caracterização das políticas públicas vigentes no Brasil até o início dos anos 80 (DRAIBE, 1997), e pela identificação da agenda de reforma que influenciou a formulação, a partir do final da década passada, de propostas alternativas e de iniciativas inovadoras por parte dos governos locais.

\section{Características das políticas públicas até o início dos anos 80}

As políticas públicas promovidas pelo Estado Brasileiro até o início dos anos 80 se caracterizavam, em primeiro lugar, pela centralização decisória e financeira na esfera federal, cabendo aos Estados e municípios - quando estes eram envolvidos em uma política específica o papel de executores das políticas formuladas centralmente. Por outro

\footnotetext{
${ }^{1} \mathrm{O}$ sentido deste processo de descentralização não está dado de antemão, havendo projetos alternativos em disputa, dentre os quais está presente também o "projeto" de reafirmação de práticas clientelistas no nível local.

2 Para a análise de inovações de governos locais serão considerados, de forma privilegiada, programas inscritos no Gestão Pública e Cidadania, programa de premiação e disseminação de experiências inovadoras de governos subnacionais, uma iniciativa conjunta da Fundação Getulio Vargas de São Paulo e da Fundação Ford, desenvolvido pela seguinte equipe: Peter Spink, diretor; Marta Ferreira Santos Farah, vice-diretora; Vivianne Nouvel Alessio, coordenadora executiva; Fabiana Paschoal Sanches, Marlei de Oliveira, Juliana Maria Paris Spink, Helio Batista Barbosa, Luis Mario Fujiwara, Maria Beatriz de Araúdo Asperti, Paulo Jábali, Patrícia Laczinski, Fernanda Martinez de Oliveira e Ilka Camarottti, coordenadora do subprograma Práticas Públicas e Pobreza. Fizeram parte da equipe em anos anteriores: Nelson Luís Nouvel Alessio, Ricardo Ernesto Vasquez Beltrão, Roberta Clemente, Sabrina Baracchini, Ana Paula Macedo Soares e Carlos Eduardo Evangelisti Mauro.
} 
lado, à medida que os recursos eram controlados pelo governo federal, e que as esferas locais de poder eram expostas diretamente a necessidades e demandas dos cidadãos, tendia a estabelecer-se uma articulação entre governos estaduais e municipais e governo federal baseada na troca de favores de cunho clientelista, em que muitas vezes as instâncias locais do poder público transformavam-se em agenciadores de recursos federais para o município ou Estado, procurando garantir a implementação de determinada política pública para sua clientela. Embora estes mecanismos tenham se intensificado durante a Nova República, já se faziam sentir nos anos 70, durante a vigência do regime autoritário. As políticas públicas eram marcadas, em segundo lugar, pela fragmentação institucional. O crescimento do aparato estatal se deu de forma desordenada, por sobreposição de novas agências a agências pré-existentes, sem que se estabelecesse coordenação da ação dos diversos órgãos. Esta desarticulação ocorria tanto no âmbito de um mesmo nível de governo, como entre diferentes esferas de governo. Tal desenho institucional dificultava a tarefa de coordenação, com implicações para a eficiência e a efetividade das políticas públicas.

Um terceiro componente das políticas públicas no campo social era seu caráter setorial. Ao longo do processo de constituição da estrutura de provisão de serviços públicos no país, sobretudo a partir dos anos 60, ocorreu a discriminação progressiva de estruturas especializadas em cada área de atuação governamental - educação, saúde, habitação, transportes etc. Se, por um lado, a constituição destas estruturas resultou do reconhecimento da crescente complexidade da problemática social no país, a exigir respostas que considerassem a singularidade dos desafios de cada uma das áreas sociais, de outro, esta especialização acabou se traduzindo em autonomia, cada política social e cada setor de serviço público sendo concebidos de forma independente dos demais, sem uma articulação entre as ações das diferentes áreas. Disto decorria, não apenas a perda de potenciais efeitos positivos de ações coordenadas dirigidas a um mesmo público-alvo, mas também o comprometimento de determinadas políticas, pela inexistência de serviços complementares de outro setor, como é o exemplo de ações na área da habitação, não acompanhadas, no curto e mesmo no médio prazo, pela implantação de infra-estrutura e de equipamentos coletivos.

Outra característica central das políticas sociais vigentes no Brasil até os anos 80 consiste na exclusão da sociedade civil do processo de formulação das políticas, da implementação dos programas e do controle da ação governamental. Quando se fala neste processo de 
exclusão, é preciso ter em mente, no entanto, que havia, no padrão então estabelecido, mecanismos de articulação entre Estado e Sociedade. O processo decisório relativo a políticas e programas envolvia a presença significativa de três das "gramáticas" que, segundo NUNES (1997), estruturam a relação Estado e Sociedade no país: o clientelismo, o corporativismo e o insulamento burocrático.

Assim, a implementação de programas e a alocação de recursos ora eram influenciadas pela relação entre políticos e sua clientela, na base de troca de favores ${ }^{3}$, ora pela lógica corporativa típica da "cidadania regulada" (SANTOS, 1979). Por outro lado, nas agências ligadas a políticas sociais em que se estabeleceu certo "insulamento burocrático" - no esforço de isolar o processo decisório das pressões políticas de cunho corporativo e clientelista - ocorreu a constituição de “anéis burocráticos" (CARDOSO, 1975), estabelecendo-se vínculos entre a burocracia destas instituições e segmentos da burguesia nacional e internacional, com impacto sobre o processo decisório e sobre a implementação das políticas.

As políticas públicas promovidas pelo Estado incorporavam, portanto, interesses da sociedade civil e do mercado: no entanto, tal incorporação era excludente e seletiva, beneficiando segmentos restritos dos trabalhadores e interesses de segmentos do capital nacional e internacional. O próprio insulamento burocrático não era imune a este processo de "inclusão seletiva" de interesses. Como mostra DINIZ (1996):

“... a estratégia do insulamento burocrático revela-se irrealista, se considerarmos que a meta almejada, qual seja, implementar escolhas públicas imunes às pressões dos interesses particulares, não é factível. Tudo o que se consegue é eliminar alguns interesses em benefício de outros, em geral os que detêm maior poder de barganha...” (p. 23).

Ao se destacar a exclusão da sociedade civil dos processos envolvidos na formulação, implementação e controle das políticas públicas, procura-se, portanto, chamar a atenção para um padrão não-democrático de articulação Estado-Sociedade, que só veio reforçar um dos elementos constitutivos do modelo de proteção social instaurado durante os anos 60 - a exclusão de amplos segmentos da sociedade do acesso a bens e serviços públicos. Neste padrão não-democrático, sobressaem a opacidade e impermeabilidade das políticas e

\footnotetext{
${ }^{3}$ Do gênero de troca entre "patron" ou "coronéis" e clientes, típico da troca generalizada, baseada em laços pessoais, em que a troca sempre é acompanhada por promessas e expectativas de ganhos futuros. Trata-se de uma troca assimétrica, na qual o acesso a benefícios decorre da relação pessoal com o político e do arbítrio deste último. Distingue-se da "troca específica", segundo a qual prevalece o universalismo de procedimentos, outro tipo de "gramática" que influencia (embora com abrangência pouco expressiva) as relações Estado-Sociedade no Brasil. (NUNES, 1997).
} 
agências estatais ao cidadão e a ausência de mecanismos de controle da ação estatal, traços constitutivos do regime autoritário*, o que reforçou a tendência ao comprometimento das metas de eqüidade, assim como introduziu no sistema um crescente déficit de accountability e de responsabilidade pública (DINIZ, 1996, DINIZ, 1999).

A máquina estatal através da qual se implementavam as políticas caracterizava-se por um padrão de gestão hierarquizado, restringindo-se o espaço para a participação das instâncias mais próximas ao cidadão. Embora originalmente este padrão tenha sido concebido sob inspiração do modelo da burocracia weberiana, que buscava garantir uma uniformização de procedimentos de corte democrático, o que ocorreu foi que, aquilo que restou destes princípios acabou funcionando como mecanismo de distanciamento entre usuários e agentes públicos e como mecanismo de padronização de respostas, contribuindo para a perda de eficácia e de qualidade. Reforçava-se, através deste distanciamento, a falta de accountability dos sistemas públicos.

Finalmente, constitui um aspecto importante do sistema de proteção social vigente no país até os anos 80 o modelo de provisão estatal. Ainda que contingentes expressivos da população tenham ficado à margem dos programas sociais estatais no Brasil, buscando soluções "autônomas" para seus problemas na área social ou ficando simplesmente excluídos do acesso a serviços públicos, o paradigma que inspirou a construção do sistema de proteção social no país foi o do Estado do Bem-Estar, implantado nos países centrais no pós-guerra, em que cabe ao Estado a responsabilidade pela provisão de bens e serviços públicos, dada a insuficiência das respostas oferecidas pelo mercado e diante da fragilidade da sociedade civil perante os enormes desafios na área da reprodução social. Este modelo, hegemônico nos países capitalistas ocidentais no pós-guerra, teria sido responsável, inclusive, pelo refluxo de iniciativas da sociedade civil e do mercado, sendo vista a proteção social, no limite, como responsabilidade exclusiva do Estado.

A revisão deste modelo fora proposta, já no final dos anos 50 , por agências multilaterais de financiamento como o Banco Mundial, para o caso de países em desenvolvimento, recomendando-se o envolvimento da sociedade civil na busca de "soluções" para os problemas sociais nestes países, como estratégia de enfrentamento da escassez de recursos nas nações do Terceiro Mundo e, mais ainda, como estratégia de minimização dos riscos de uma explosão social nestes países. No Brasil, prevaleceu, no entanto, até os anos 80, 
como paradigma a servir de referência à formulação das políticas públicas, o modelo centrado na provisão estatal.

\section{A agenda da reforma das políticas sociais}

O debate sobre a reforma da ação do Estado na área social, no Brasil, teve início na década de 70 e ganhou impulso nos anos 80 , no âmbito do processo de democratização do país. A agenda de reforma que então se definiu, inspirando iniciativas inovadoras por parte de governos estaduais de oposição partir de 1982 e se consolidando na Constituição de 88, teve com eixos a democratização dos processos decisórios e a eqüidade dos resultados das políticas públicas, sendo a democratização vista como condição da eqüidade dos resultados.

Tratava-se, neste momento, de implementar mudanças não apenas no regime político, mas também no nível das políticas públicas, do Estado em ação (O’DONNEL, 1989), procurando-se superar as características críticas do padrão brasileiro de intervenção do Estado na área social, indicadas anteriormente ${ }^{4}$.

As propostas enfatizadas, neste momento, foram a descentralização e a participação dos cidadãos na formulação e implementação das políticas. Como mostra DRAIBE ${ }^{(1992)}$, do ponto de vista da orientação substantiva das políticas sociais, procurava-se caminhar, sob o impulso das forças democratizantes, para um Estado do Bem-Estar do tipo institucionalredistributivista, caracterizado pela concepção universalista de direitos sociais, uma vez que o sistema de proteção social implantado no país caracterizava-se por seus traços corporativistas - aos quais se agregavam outras formas de segmentação da população - e pela exclusão de amplos contingentes da população do acesso à cidadania social. A descentralização e a participação eram vistos como ingredientes fundamentais desta reorientação substantiva das políticas sociais, voltada para a garantia da eqüidade e para a inclusão de novos segmentos da população na esfera do atendimento estatal.

Participaram da constituição desta agenda movimentos sociais, constituídos desde os anos 70, em torno tanto de questões gerais relativas à democratização do regime como de uma pauta específica de reivindicações por serviços públicos, de cujo acesso seus membros

\footnotetext{
${ }^{4}$ Privilegiou-se na identificação destas características aspectos institucionais e relativos ao processo de articulação entre Estado e Sociedade. É preciso destacar ainda, como aspecto substantivo do padrão de proteção social vigente até os anos 80, a gestão das políticas sociais a partir de uma lógica financeira, levando à segmentação do atendimento e à exclusão de amplos contingentes da população do acesso aos serviços públicos.
} 
estavam excluídos. Foram também atores importantes na constituição da agenda de reforma determinadas categorias profissionais envolvidas na prestação de serviços públicos (médicos sanitaristas, educadores, assistentes sociais e profissionais da área de habitação e saneamento), cuja atuação os colocava em contato direto com a população atendida pelo Estado e sobretudo com a realidade dos excluídos do atendimento estatal.

No final da década de 80 e início dos anos 90, já sob o impacto da crise fiscal, a escassez de recursos passou a ser uma questão central, ao limitar a capacidade de resposta do Estado às demandas crescentes na área social. Assim, ao lado da preocupação com a democratização dos processos e com a eqüidade dos resultados, foram introduzidas na agenda preocupações com a eficiência, a eficácia e a efetividade da ação estatal, assim como com a qualidade dos serviços públicos.

Neste processo de redefinição da agenda de Reforma, disputou espaço internamente o ideário neoliberal, que ganhara força nos países centrais e nas agências multilaterais de financiamento. Segundo esta perspectiva, o Estado é essencialmente ineficiente, ineficaz e provedor de serviços de baixa qualidade. A crise econômica - e a crise do Estado resultam do próprio Estado e de sua intervenção excessiva. A interpretação da crise na América Latina e no Brasil, segundo a leitura neoliberal, foi consubstanciada nas doutrinas do "Consenso de Washington", segundo as quais foi o próprio Estado NacionalDesenvolvimentista o gerador da crise nestes países, sendo os programas de ajuste orientados, portanto, para o "desmantelamento" deste Estado e para reformas que reduzam o tamanho do Estado, desregulamentem a economia e garantam a abertura do mercado (PORTELLA FILHO, 1994).

Com relação especificamente à área social, a agenda neoliberal propõe: a) a privatização, através da transferência da produção de serviços públicos para o setor privado lucrativo; b) a descentralização das políticas sociais para as esferas locais de governo, como forma de aumentar a eficiência e a eficácia do gasto público; c) a focalização, orientada para a concentração da ação estatal em determinados serviços (considerados essenciais e não passíveis de oferta pelo mercado) e em segmentos específicos da população, mais vulneráveis e expostos a situações de pobreza extrema (DRAIBE, 1993) e d) mudanças na gestão dos programas estatais, de forma a dotá-las da eficiência e eficácia atribuída à gestão privada (FARAH, 1998a). 
As propostas de corte neoliberal se contrapõem à agenda formulada anteriormente, orientada para a democratização e para construção no país de um Estado do Bem-Estar universalista $^{5}$. No entanto, a crise que atingiu o país desde o início da década de 80 e alterações na economia capitalista mundial, em que se destacam a reestruturação produtiva e a globalização, redefinindo os termos da inserção do Brasil no cenário internacional, vieram colocar novos desafios aos atores que haviam participado internamente da formulação da agenda democrática e estavam engajados com a efetivação da reforma. Assim, ao mesmo tempo que a Constituição de 1988 assinalava a transposição para o plano legal de grande parte da agenda que se fora construindo desde a década anterior, já se assistia a uma reformulação desta agenda, através da incorporação de novos desafios.

Diferentemente da abordagem neoliberal, esta agenda não pretende, no entanto, o desmantelamento do Estado, mas sim uma reforma da ação estatal, que venha adequá-la aos novos desafios que se apresentam a uma nação em desenvolvimento neste final de século. No início da década de 90, procurava-se, portanto, integrar à agenda "democrática" dos anos 80 novos ingredientes, voltados à busca da eficiência, da eficácia e da efetividade na ação estatal. Assim, alguns dos componentes da proposta neoliberal para a reforma das políticas sociais são integrados pela agenda democrática (DRAIBE, 1993), assumindo um novo significado.

Não se trata, neste caso, de privatização como alternativa prioritária ou exclusiva (potencialmente segmentadora e excludente), mas de novas formas de articulação com a sociedade civil e com o setor privado, visando à garantia da provisão de serviços públicos (ou a construção de novas modalidades de solidariedade social (LIPIETZ, 1991), ocorrendo a substituição do modelo de provisão estatal por um modelo em que o Estado deixa de ser o provedor direto exclusivo e passa a ser o coordenador e fiscalizador de serviços que podem ser prestados pela sociedade civil ou pelo mercado ou em parceria com estes setores.

Da mesma forma, a descentralização não significa apenas transferir atribuições, de forma a garantir eficiência, mas é vista sobretudo como redistribuição de poder, favorecendo a democratização das relações entre Estado e Sociedade e a democratização do acesso aos serviços.

\footnotetext{
${ }^{5}$ Ainda que a descentralização seja uma plataforma comum, assume significados distintos em uma e outra perspectiva, como ficará claro a seguir.
} 
A focalização, por sua vez, é incorporada pelo reconhecimento da necessidade de se estabelecerem prioridades de ação em contexto de limites de recursos e por se entender que é preciso atender de forma dirigida alguns segmentos da população, que vivem situações de carência social extrema. No entanto, as políticas seletivas devem ser entendidas como complementares a políticas universais de caráter redistributivo e a políticas de desenvolvimento orientadas para a superação de desigualdades estruturais.

Do mesmo modo, pode-se dizer que a reformulação da gestão estatal tampouco é monopólio do neoliberalismo, sendo incorporada à agenda de reforma neste segundo momento por atores que defendem a democratização das políticas públicas e a eqüidade das políticas sociais. Nesta perspectiva, no entanto, a preocupação com a eficiência e com a eficácia se articula à orientação para a eqüidade e para a democratização dos processos decisórios, envolvendo tanto alterações institucionais - com ênfase à descentralização como novos padrões de relação entre Estado e Sociedade.

Alguns elementos de proposta da CEPAL para a América Latina, formulada no início da década de $90^{6}$, em torno da noção de transformação produtiva com eqüidade, podem ser tomados como referência da redefinição da agenda de Reforma das Políticas Sociais que se desenha no país desde o final da década de 80. Tais elementos são assim resumidos por ARRETCHE (1993):

a) Estabelecimento de metas coordenadas entre política econômica e política social;

b) Definição de metas próprias para a política social, que não deve ser meramente reativa à crise mas orientar-se para a integração da população aos benefícios do desenvolvimento;

c) Articulação de programas sociais universais a programas seletivos. Diferentemente da proposta neoliberal, a política social não é concebida como exclusivamente focalizada. Embora se reconheça a seletividade, enquanto critério de atendimento a "setores vulneráveis", não se abre mão da universalidade em áreas como saúde, educação e nutrição.

d) Integração da política social ao projeto de desenvolvimento. Não se concebe a política social como alívio de situações de pobreza extrema, sobretudo como atenuante dos efeitos perversos do ajuste. Entende-se, ao contrário, que a política social tem importantes impactos sobre o desenvolvimento, enquanto investimento em capital humano, o que inclui investimentos em saúde, nutrição, remuneração, além da educação, que, num momento de reestruturação produtiva, cumpre um importante papel na requalificação da mão-de-obra.

e) Articulação entre programas sociais, de forma a consolidar um sistema de proteção social;

${ }^{6}$ Uma avaliação da década de 90, da perspectiva de técnicos da CEPAL, pode ser vista em FRANCO (1999). 
f) Racionalização do gasto social, de modo a se obter maior eficiência e maior efetividade. Tal racionalização envolve a articulação entre o setor público e o setor privado para a prestação de serviços sociais, havendo a transformação do modelo de provisão estatal, para uma provisão em que o Estado deixa de ser o provedor direto exclusivo e passa a ser o coordenador e fiscalizador de serviços estabelecidos a partir da interação entre agentes públicos e privados.

Em relação à gestão estatal, foram incorporadas à agenda as seguintes diretrizes: a) democratização interna da máquina pública, com alterações no processo de tomada de decisão centralizado; b) estímulo à inovação, substituindo-se os processos rotinizados de estrito cumprimento da norma; c) aproximação entre as entidades prestadoras de serviços e os cidadãos-usuários, envolvendo capacidade de responder a necessidades não massificadas, transparência e possibilidade de controle, além de mecanismos de participação na gestão dos próprios serviços; d) estabelecimento de uma política de valorização de recursos humanos, que viabilize a dignificação da função pública, a qual deve incluir necessariamente programas de formação e requalificação do pessoal do Estado; e) descentralização da máquina pública, medida que contribuirá para a democratização e para a melhor resposta da administração a necessidades regionalizadas (KLIKSBERG, 1994 e DOWBOR, 1994).

Draibe, analisando a emergência desta nova agenda, mostra como, embora se mantenha a meta de garantia de direitos sociais para todos, há uma redefinição da forma de se garantirem estes direitos, assumindo um lugar central nesta redefinição o envolvimento de novos atores na própria prestação dos serviços (DRAIBE, 1992, p. 68):

"Um segundo aspecto da questão refere-se à forma e aos mecanismos através dos quais tender-se-á, no Brasil, a garantir o efetivo cumprimento dos direitos sociais recentemente ampliados. ... A questão, hoje, é como ampliar a responsabilidade estatal na área social sem necessariamente arcarmos com os recorrentes problemas de gigantismo, burocratismo, autonomizações indevidas, ausências de controles. E isso numa época em que a sensibilidade social e da opinião pública para tais questões aumentou enormemente; em que, por outro lado, os discursos e as posturas liberais privatizantes vêm ganhando amplo espaço e em que, finalmente, foram alteradas e ampliadas as possibilidades de envolvimento de formas organizadas da sociedade na própria operação dos serviços sociais, apontando para modos distintos de organização e equilibrio entre o Estado, o setor privado lucrativo e o setor privado não-lucrativo na produção e distribuição de bens e serviços sociais". Estão ai contemplados, a nosso ver, os temas de nova agenda de reformas dos anos 90 ". 
Assim, no final dos anos 80 e nos anos 90, as propostas se redefiniram, sendo enfatizadas além das teses de descentralização e de participação - a necessidade de estabelecimento de prioridades de ação; a busca de novas formas de articulação com a sociedade civil e com o mercado, envolvendo a participação de ONG, da comunidade organizada e do setor privado na provisão de serviços públicos; e a introdução de novas formas de gestão nas organizações estatais, de forma a dotá-las de maior agilidade, eficiência, e efetividade, superando a rigidez derivada da burocratização de procedimentos e da hierarquização excessiva dos processos decisórios.

A emergência daquilo que Peter Evans designa como a Terceira Onda de pensamento sobre o Estado (EVANS, 1993) sugere que, nos países desenvolvidos e em algumas das agências multilaterais, caminha-se para a revisão do consenso minimalista a respeito do Estado. Nesta revisão, as políticas públicas de caráter social tendem a ganhar novamente centralidade. $\mathrm{O}$ desenho destas políticas já não será o mesmo que prevaleceu no paradigma anterior, tendendo a haver uma incorporação do debate das últimas duas décadas. Nesta reconstrução da agenda, em que a ação estatal readquire legitimidade, os eixos indicados acima tendem a ser reforçados (IGLESIAS, 2000, KLIKSBERG, 2000).

\section{Iniciativas inovadoras de governos locais}

O processo de redefinição da ação do Estado no Brasil, em particular de sua ação na área social, teve como um de seus marcos iniciais a eleição de governos estaduais de oposição em 1982, embora estes ainda estivessem fortemente condicionados pelo arcabouço institucional do período autoritário. Prosseguiu através de iniciativas de reforma promovidas pelo governo federal durante a Nova República, as quais retrospectivamente tendem hoje a ser vistas antes como início de um processo de "desmonte" das estruturas de provisão implantadas no período anterior, que propriamente como reforma. A partir da democratização e sobretudo da Constituição de 1988, identifica-se finalmente um movimento mais abrangente de reforma que envolve iniciativas de todas as esferas de governo. Intensificam-se sobretudo as iniciativas de governos municipais, que ampliam significativamente sua ação no campo das políticas sociais, promovendo ainda programas voltados ao desenvolvimento local.

A importância crescente da ação municipal na área social nos últimos anos pode ser atribuída, entre outros, aos seguintes fatores: 
1. transferência de atribuições e competências do governo central e da esfera estadual de governo, para o governo municipal, com ênfase às atribuições que dizem respeito à cidadania social ${ }^{7}$;

2. resposta a reivindicações da sociedade civil pela descentralização das políticas sociais, desde o início da década de 80;

3. ênfase à descentralização na agenda de reforma de diferentes correntes políticas;

4. aumento significativo da participação dos municípios na repartição dos recursos fiscais desenhada a partir da Constituição de $1988^{8}$;

5. ênfase à descentralização na agenda de organismos financiadores multilaterais, os quais exercem influência sobre o desenho das políticas governamentais no país;

6. maior proximidade do governo local com relação às demandas da população, o que assume relevância num quadro democrático;

7. insuficiência das respostas do mercado como alternativa ao "desmonte" do Estado (e de suas políticas) no nível federal e "necessidade", portanto, de formulação de respostas no nível local.

Ao lado da crescente importância da ação no campo das políticas sociais, alguns municípios passam a promover também programas de desenvolvimento local, ampliando ainda mais a agenda municipal nos anos 90 .

O deslocamento de iniciativas de políticas sociais para esferas subnacionais de governo não é um processo isento de problemas. A descentralização, em primeiro lugar, não ocorre de forma homogênea em todo o país, sendo bastante diversificada a capacitação municipal para fazer frente aos novos desafios ${ }^{9}$. Variam também significativamente os graus de descentralização entre as diferentes políticas sociais, como reflexo de um conjunto de fatores, dentre os quais se destacam o arcabouço institucional vindo do período anterior e o grau de indução da descentralização exercido pelos governos estaduais e pelo governo federal (ARRETCHE, 1998). Finalmente, o grau de descentralização e a forma como esta se dá são também afetados por uma dinâmica política e social interna a cada localidade, em que têm lugar relevante as pressões exercidas pela sociedade civil sobre o governo local e o próprio projeto político de cada gestão.

Esta heterogeneidade chama a atenção para a necessidade de se preservarem políticas de coordenação em níveis mais abrangentes de governo, que minimizem desigualdades e garantam a busca de projetos regionais e de um projeto nacional.

\footnotetext{
${ }^{7}$ É sabido que este processo de transferência está longe de estar concluído, havendo uma série de ambigüidades na definição de competências e no processo de transferência de recursos, o que tem dificultado a promoção de políticas dotadas de maior efetividade.

${ }^{8}$ Aqui também a situação não é isenta de dificuldades, uma vez que, ao longo do período, em diferentes setores das políticas sociais, houve alterações na legislação federal, conduzindo a certa recentralização de recursos, com dificuldades para o cumprimento pela esfera local de suas novas atribuições.

9 Ver também notas 5 e 6 .
} 
Por outro lado, a descentralização nem sempre tem significado a superação de características críticas do padrão anterior de relação Estado-Sociedade, podendo ser citado, a título de exemplo, a intensificação de práticas clientelísticas em alguns municípios.

Mas, a descentralização e a intensificação da importância dos governos locais têm sido acompanhadas também pela emergência de novas práticas políticas e de administração pública, orientadas a um só tempo para a eqüidade e para uma maior eficiência da ação estatal. Neste processo embrionário de reforma da ação estatal no país, os governos locais têm contribuído para a formatação de novos arranjos institucionais e de novos processos de gestão em que se rompem alguns dos elementos críticos que caracterizavam as políticas sociais até os anos 80 .

Uma primeira mudança significativa no desenho das políticas sociais implementadas por governos locais consiste na promoção de ações integradas, dirigidas a um mesmo públicoalvo. Focaliza-se uma área de intervenção ou um segmento da população, procurando-se formular políticas integrais - articulando ações tradicionalmente fragmentadas em diversos campos ou setores. A promoção de políticas sociais com esta perspectiva significa, em geral, a superação da setorialização e da fragmentação institucional, procurando-se coordenar a ação de diversas secretarias e órgãos, cuja ação até então era segmentada ou justaposta, com perda de eficiência e de efetividade das políticas.

São diversos os programas municipais que adotam esta abordagem, tais como os programas dirigidos a crianças e adolescentes e os que têm como foco a mulher. No caso de programas para crianças e adolescentes em situação de risco social e pessoal, procura-se prestar um atendimento integral, envolvendo aspectos como formação profissional, reinserção na escola e na família, acompanhamento na área de saúde, orientação sexual etc. Há exemplos de programas com esta perspectiva em todo o país, como o projeto Miguilim, de Belo Horizonte, o programa Cidade Mãe, de Salvador, o Projeto Criança, de Jundiaí, em São Paulo e o programa Sobral Criança, de Sobral, no Ceará.

Os programas com foco na problemática da mulher também são cada vez mais freqüentes, envolvendo, sobretudo no caso dos que têm como alvo o combate à violência contra a mulher, uma ação coordenada nas áreas jurídica, psico-social, da saúde e da educação. Tal é o caso dos programas Casa Rosa Mulher, de Rio Branco, no Acre e Casa do Caminho, de Fortaleza, no Ceará. 
Há ainda iniciativas que surgem em torno de uma problemática setorial específica, como a da habitação, e acabam assumindo uma dimensão mais abrangente, através da opção por uma abordagem integral. Tal é o caso, por exemplo, do programa Ação Integrada nos Bolsões de Pobreza Urbanos, desenvolvido pela Prefeitura Municipal de Ipatinga, em Minas Gerais, o qual inclui, além da produção de moradias em regime de autogestão, o desenvolvimento de atividades nas áreas de saúde, educação, meio ambiente, geração de emprego e renda etc., com o objetivo de permitir o desenvolvimento integral da comunidade atendida. Estas atividades são promovidas através da ação integrada de uma equipe multidisciplinar e da coordenação da ação de diversas secretarias municipais. Constitui outro exemplo o Projeto São Pedro - Desenvolvimento Urbano Integrado e Preservação do Manguezal, programa do Município de Vitória, no Espírito Santo, o qual procura melhorar as condições de vida de população de baixa renda que vive em região de manguezal, através de ações coordenadas nas áreas de habitação, infra-estrutura, meio ambiente, saúde, educação etc.

Outros exemplos de ações que integram políticas tradicionalmente segregadas são: o Programa Bolsa Familiar para a Educação, Bolsa-Escola, desenvolvido de forma pioneira pelo governo do Distrito Federal, em que se procura articular o combate à evasão e à repetência à complementação da renda familiar: o programa consiste na concessão de uma bolsa de cerca de um salário-mínimo a famílias de renda baixa (no Distrito Federal, de renda inferior ou igual a $1 \frac{1}{2}$ salário-mínimo), desde que estas mantenham seus filhos na escola; o Programa de Saúde Global, de Joaíma, em Minas Gerais, dirigido à população rural do município, integrando ações na área da saúde - incluindo assistência médica, medidas de caráter preventivo e de formação para a saúde - a ações em outras áreas, como assistência a pequenos produtores rurais e confecção de documentos e o Programa Lixo que não é Lixo (Câmbio Verde), de Curitiba, no Paraná, em que o programa de coleta seletiva de lixo se articula a ação na área de abastecimento e de apoio ao pequeno produtor rural, através da troca de lixo reciclável por produtos hortifrutigranjeiros produzidos no cinturão verde da cidade. O programa articula, assim, uma ação na área de saneamento e meio ambiente aos seguinte objetivos: facilitar o escoamento da safra de produtos hortifrutigranjeiros da região e propiciar hábitos alimentares de melhor valor nutritivo para a comunidade envolvida.

Estas iniciativas parecem assinalar o reconhecimento de que a eficácia de uma política setorial passa muitas vezes pela consideração de questões externas ao próprio setor - como 
é o caso do programa Bolsa-Escola, em que se reconhece que a evasão e a repetência não resultam exclusivamente de características do ensino oferecido, mas dependem também da inserção sócio-econômica da família. De forma complementar, entende-se que a modificação da situação econômica das famílias passa pela educação.

Em alguns casos, como no projeto de desenvolvimento urbano mencionado e nos destinados a crianças e adolescentes, a concepção de ação integral é constitutiva da própria formulação da política, por se entender que os objetivos almejados só serão atingidos dada a profundidade da exclusão dos segmentos de população atendidos - se a ação for de caráter múltiplo.

Outro aspecto que se destaca em programas recentes promovidos por governos municipais consiste no estabelecimento de vínculos de parceria com outros níveis de governo e com governos de outros municípios. Como visto anteriormente, no modelo anterior de provisão de serviços públicos e de promoção de políticas sociais, a esfera local tendia a ser mera executora de programas federais. Em iniciativas recentes, identificam-se, de um lado, iniciativas de governos municipais que procuram aliados nas esferas mais abrangentes de governo e, de outro, programas locais articulados a políticas estaduais ou federais.

Dentre os inúmeros exemplos de iniciativas da esfera local que buscam articulação com níveis mais abrangentes de governo pode ser citado o programa Portosol, desenvolvido pela Prefeitura de Porto Alegre. Este programa - voltado à concessão de crédito a pequenos e microempresários excluídos do acesso aos canais tradicionais de financiamento - contou, desde sua implantação, com o apoio do governo estadual. Outro exemplo de articulação intergovernamental consiste na Câmara do Grande $A B C$, iniciativa de prefeituras da região da Grande São Paulo, que procura formular e implementar de forma colegiada um plano de desenvolvimento sustentável regional, e que envolve, entre os seus participantes, além de sete municípios da região, representantes do governo do Estado.

O caso de saúde constitui um exemplo importante da articulação de diretrizes emanadas do governo federal a uma dinâmica local de formulação e implantação de programas sociais. O programa Médico de Família se insere na perspectiva de consolidação do SUS Sistema Único de Saúde, procurando substituir o modelo de saúde de caráter assistencial vigente no país. A origem deste programa nos municípios brasileiros é bastante diversificada: em alguns, o programa se constituiu como iniciativa do município - equipes de saúde, movimentos sociais locais - que foi buscar inspiração fora do país, como é o 
caso do programa Médico de Família, de Niterói, implantado em 1992. Em outros casos, como em Londrina, no Paraná, onde o programa data de 1995, a implantação do programa já se deu sob influência de diretrizes do Ministério da Saúde, como parte integrante de um processo de indução da descentralização da política de saúde. Isto não quer dizer, no entanto, que o papel do município se resuma, neste último caso, à mera execução de um programa federal ou que a adesão ao programa e à descentralização seja meramente reativa. Em primeiro lugar, através da descentralização de recursos e de poder de decisão, procura-se, no caso da iniciativa federal, permitir que o programa assuma a feição de cada localidade em que for implantado. Por outro lado, há uma articulação das diretrizes federais ao processo de formulação local de programas e políticas para o setor. Em Londrina, as diretrizes gerais do programa Médico de Família eram consistentes com um processo local de busca de alternativas para a área de saúde. O município foi capaz de se apropriar do programa de forma autônoma e consistente com sua filosofia básica: implantar um novo modelo de saúde, de ênfase preventiva e orientado para a formação para a saúde, em que a relação entre equipe de saúde e comunidade é mais próxima, ultrapassando o atendimento ambulatorial. Há autonomia na execução, autonomia financeira e autonomia na gestão do programa - que é articulado a um plano de saúde municipal, acompanhado pelo Conselho Municipal de Saúde.

Mas é preciso ter esta dinâmica interna consolidada, envolvendo a construção de um consenso local quanto ao novo modelo de saúde, para que a ação do município se articule às diretrizes federais com autonomia, propiciando, por outro lado, efetividade ao programa. Como afirma MELAMED (1997) a respeito da adoção do Médico de Família em outras localidades:

"Nem todos os programas implantados até o momento apresentam a mesma qualidade. Em algumas regiões, eles são orientados, por exemplo, para fins estritamente eleitorais, com resultados discutíveis, ou são vistos como programas que visam ... substituir a rede existente e, em vez de colaborarem para uma utilização mais equilibrada dos recursos públicos, acabam por gerar maior desperdício”. ((p.138)

Com relação, por sua vez, à articulação entre governos de diferentes municípios, já são várias as experiências no país do tipo consórcio intermunicipal, em que vários municípios se reúnem em torno de objetivos comuns, procurando formular, de forma conjunta, planos para enfrentamento de questões que ultrapassam a capacidade de resolução de um município isolado. Dentre estas experiências, podem ser citadas: a) o Consórcio Intermunicipal da Microregião de Penápolis, no Estado de São Paulo, constituído, em 
1987, por sete municípios da região (Alto Alegre, Avanhandava, Barbosa, Braúna, Glicério, Luiziânia e Penápolis), em torno da questão de saúde (CRUZ, 1992); b) o Consórcio Intermunicipal do Grande $\mathrm{ABC}$, que reúne sete municípios (Santo André, São Bernardo, São Caetano, Diadema, Mauá, Ribeirão Pires e Rio Grande da Serra), com o objetivo de desenvolver uma gestão regional conjunta, procurando tratar de forma integrada questões como tratamento e destinação de resíduos sólidos, abastecimento de águas, saneamento básico e ambiental etc.... e c) o Consórcio Intermunicipal da Bacia Hidirográfica do Alto Rio Negro Catarinense, voltado para a superação de problemas ambientais, sobretudo relativos ao tratamento de resíduos sólidos, envolvendo três municípios de Santa Catarina (Rio Negrinho, Campo Alegre e São Bento do Sul).

A articulação entre governos municipais e entre diferentes esferas de governo assinala a possibilidade de estabelecimento de um novo tipo de vínculo intergovernamental, distinto do que vinha caracterizando as políticas sociais no país - marcando ora pelo clientelismo ou pelo predomínio da atribuição aos municípios da função de meros executores - sem voz - de políticas federais. Neste novo vínculo - de parceria - há uma co-responsabilização pela política e seus resultados, ainda que a cada um dos participantes possam caber papéis diferenciados ao longo do processo de implementação das políticas.

A parceria interna ao próprio Estado parece estar ocorrendo sob duas formas: de um lado, através da articulação intersetorial, apontada anteriormente. De outro, através da articulação intergovernamental, seja esta vertical (entre níveis distintos de governo), seja horizontal (entre governos de um mesmo nível). Estudo recente de SPINK, CLEMENTE e KEPPKE (1998) revela que, dentre 200 programas selecionados como semifinalistas em programa de premiação de iniciativas inovadoras de governos subnacionais (Gestão Pública e Cidadania), 73,5\% envolviam algum tipo de parceria entre agências de governo. Parece estar se constituindo uma novo processo de formulação e implementação de políticas públicas, baseado em arranjos institucionais que envolvem a ruptura do modelo centrado em instituições ou agências isoladas, cuja relação com outras agências tendia a se caracterizar pela subordinação (com agências de níveis mais abrangentes de governo) ou pela disputa por espaços junto a clientelas (agências de mesmo nível de governo).

Mas a construção de novos arranjos institucionais só se completa com um outro elemento inovador presente em diversas experiências municipais recentes: o estabelecimento de novas formas de articulação entre Estado, sociedade civil e mercado. Através destas novas formas de articulação, observa-se uma tendência à inclusão de novos atores na 
formulação e implementação das políticas públicas no nível local. A iniciativa dos municípios na área social tende hoje a incluir, em algum grau, a participação de entidades da sociedade civil - comunidade organizada, organizações não-governamentais e setor privado empresarial. Análise de 629 iniciativas de governos subnacionais inscritas no programa Gestão Pública e Cidadania mostra que mais de $40 \%$ dos programas envolviam algum tipo de parceria com a sociedade civil ou com entidades do setor privado (FARAH,1997). Segundo o estudo de SPINK, CLEMENTE E KEPPKE (1998), dentre as 200 iniciativas finalistas (dentre 926 programas inscritos em 1996 e 1997), 72,5\% caracterizavam-se pela existência de parceria com a sociedade civil ou com entidades empresariais.

Muitos dos programas governamentais subnacionais têm como um de seus elementos constitutivos ou mesmo como preocupação central a participação do cidadão na formulação, na implementação e no controle e avaliação das políticas públicas. A participação popular constitui uma das dimensões centrais da agenda de Reforma das Políticas Sociais estabelecida no início dos anos 80 no país e que inspirou a ação de governos estaduais de oposição a partir de 1982. A exclusão dos cidadãos da formulação e implementação das políticas públicas era um dos pontos enfatizados pelos críticos do padrão de proteção social até então presente no país, cuja reversão era considerada crucial para garantir maior universalização e eqüidade às políticas sociais. Propostas de reforma de diversos setores da política social, como educação, saúde, habitação, assistência social, cultura, entre outras, incluíram, a partir de então, como um dos seus componentes centrais, a participação popular, entendida como condição para o exercício pleno de direitos de cidadania. Somente assim, entendia-se, as políticas sociais poderiam deixar de ter um caráter a um só tempo excludente e paternalista.

Assim, desde o início dos anos 80, são propostos e instituídos mecanismos de gestão de políticas sociais que envolvem a participação popular, tais como os Conselhos de Saúde, e os Conselhos Municipais de Educação e os Conselhos nas próprias escolas, compostos por pais, alunos, professores e funcionários. $\mathrm{Na}$ área de habitação, por sua vez, difundem-se iniciativas do tipo mutirão, ajuda-mútua e cooperativas habitacionais, que supõem o envolvimento da população atendida na definição e acompanhamento dos projetos habitacionais. Também na área de Assistência Social, constitui-se um movimento reformador que procura reverter o modelo assistencialista, reconhecendo a comunidade a ser atendida como um dos atores da própria política. 
Nas experiências recentes de governos municipais são diversos os exemplos de iniciativas que se caracterizam pela participação do representantes da sociedade civil ${ }^{10}$. $\mathrm{Na}$ área de gestão e planejamento, vários programas envolvem a participação da população, como nos diversos casos de orçamento participativo, inspirados na experiência pioneira de Porto Alegre, podendo ser mencionados os exemplos de Soledade, no Rio Grande do Sul, Campo Mourão, no Paraná, Londrina, no Paraná, Franca, em São Paulo, Angra dos Reis, no Rio de Janeiro, Vitória, no Espírito Santo, Belo Horizonte, em Minas Gerais, e Ipatinga, também em Minas.

Diversos programas de habitação e desenvolvimento urbano incluem também a participação popular no processo decisório. O Projeto São Pedro - Desenvolvimento Urbano Integrado e Preservação do Manguezal, programa do Município de Vitória, mencionado anteriormente, constitui um exemplo. Este programa consiste em um conjunto de ações integradas nas áreas de habitação, infra-estrutura, meio ambiente, saúde, educação etc. voltadas à melhoria das condições de vida de cerca de 15.000 famílias de baixa renda e à preservação das áreas de Manguezal, ocupadas por esta população. O programa envolve, desde o início, a participação da população, através de associações de moradores e do Conselho Popular de Vitória (entidade que reúne movimentos populares).

Embora sob direção de uma entidade governamental, vários projetos se estruturam como redes de entidades e instituições, mobilizadas e articuladas em torno de um problema de interesse público, cujo enfrentamento ultrapassa a capacidade de ação isolada do Estado seja por limites financeiros ou técnicos, seja pelo maior grau de imersão no problema que uma ação coordenada permite. Assim, por exemplo, o Programa Miguilim, de Belo Horizonte, procura integrar socialmente crianças e adolescentes com trajetória de rua através da articulação da ação de um conjunto de atores - do Estado, do setor privado e da sociedade civil - os quais participam de todas as etapas do programa: desde a sua concepção até o atendimento e a fiscalização.

Outro programa com esta característica é a Câmara do Grande $A B C$, que inclui entre seus integrantes, "parceiros" na formulação de políticas públicas para a região, entidades da sociedade civil e do setor privado. Segundo documento do programa, compõem a Câmara Regional as seguintes instituições: o consórcio intermunicipal das Bacias do Alto Tamanduateí e Billings, o governo do Estado de São Paulo, o Poder Legislativo e o Fórum

\footnotetext{
${ }^{10} \mathrm{O}$ processo de inclusão da sociedade civil na formulação e implementação das políticas públicas apresenta dificuldades e limites. Estudos recentes desenvolvidos sobre programas deste mesmo banco de dados destacam alguns dos limites da participação da sociedade em parte das iniciativas subnacionais (TENÓRIO e ROZEMBERG, 1997; TENÓRIO e STORINO, 1999 e PINHO, SANTANA e CERQUEIRA, 1999 ).
} 
da Cidadania, o qual reúne mais de 100 entidades representando empresários (CIESP, Associações comerciais, etc.), trabalhadores (Sindicatos de trabalhadores e associações profissionais) e outras entidades da sociedade civil (associações de bairro, clubes, ONG etc.). (CÂMARA DO GRANDE ABC, 1998).

É importante destacar, dentre os programas que envolvem outros atores, aqueles em que a própria provisão e a gestão dos serviços ou da política pública passam a ser compartilhadas, deixando de ser atribuição exclusiva do Estado. A inclusão de novos atores na provisão de serviços se dá de forma diferenciada, segundo a área privilegiada de intervenção. Assim, a questão ambiental parece ter se configurado desde o início como problemática cujo equacionamento passa necessariamente pelo envolvimento da sociedade civil e do mercado. Assim, nos programas desta área, nota-se, de um lado, que a parceria com o setor privado é crucial, deixando as empresas de ser vistas como meras cumpridoras da legislação, sob pena de punição, para serem percebidas e se perceberem como coresponsáveis pela situação ambiental de seus municípios. Tal é o caso, por exemplo, do programa Gestão de Qualidade Ambiental do Município, programa desenvolvido pela prefeitura de Estância Velha, no Rio Grande do Sul, através de parceria com o setor privado, para redução da poluição no município, o que significou a melhoria da posição relativa do município em ranking de municípios poluidores naquele Estado - do $3^{\circ}$ maior poluidor, para a $42^{\circ}$ posição. Por outro lado, o envolvimento de outros atores inclui também a população em geral, procurando estimular-se a sua participação como coresponsável na busca de soluções para a questão ambiental, o que é buscado através de programas de educação ambiental.

Também da área ambiental é o programa Coleta de Sementes Nativas do Cerrado e Matas, de Franca em São Paulo, que envolve, além da própria prefeitura uma ONG ambientalista, grupos de escoteiros e uma fundação ligada ao setor empresarial. Destaca-se ainda o Modelo de Gestão de Residuos Sólidos, de Belo Horizonte, Minas Gerais, programa que articula uma série de ações para a coleta e o tratamento de lixo - como procedimentos técnicos de tratamento, valorização dos garis, envolvimento de catadores de papel, mobilização de empresas privadas - dentre as quais se inclui a sensibilização da população do município para a problemática ambiental associada à geração de lixo.

Nas áreas de educação e de saúde, privilegia-se o envolvimento de entidades representativas da população na gestão do sistema (saúde) e da unidade de prestação de serviço (escola). Na área de educação, esta iniciativa responde a demandas no sentido da 
democratização do sistema de educação, procurando fazer chegar a democratização até a "ponta do sistema" - a própria escola - como forma de garantir a adequação da política ao público-alvo, a melhoria da qualidade e a redução da evasão e da repetência. A participação de outros atores - conselhos municipais, conselhos nas escolas - articula-se à busca de a uma maior autonomia para a escola, para garantir eficiência e efetividade ao sistema educacional. No programa Centro de Educação Infantil Comunitário, do município de Quixadá, no Ceará, por exemplo, as unidades de educação infantil da prefeitura são gerenciadas por associações de bairro, que deliberam sobre currículo, calendário etc.

$\mathrm{Na}$ área de saúde, a proposta de reforma do sistema formulada por diversos dos atores envolvidos na área, sob a liderança de profissionais da área de saúde, desde o início dos anos 80 e consubstanciada na Constituição de 88 , atribui uma posição privilegiada ao município, ao qual cabe o papel de gestor de recursos e da própria política de saúde. Esta descentralização tem como contrapartida o envolvimento dos cidadãos - a clientela dos serviços de saúde - através de Conselhos, na definição de prioridades e na própria gestão dos recursos, forma de garantir maior eqüidade, eficiência e efetividade ao sistema e de introduzir controle sobre a ação do setor público estatal. Esta tendência se verifica em diversos programas municipais, com por exemplo, no Gestão Semiplena - SUS, programa desenvolvido em Brumadinho, no Estado de Minas Gerais e em Betim, no mesmo Estado, assim como nos programas Médico de Família, analisados anteriormente neste trabalho, em que se busca efetivar o processo de descentralização e a gestão única do sistema de saúde, com participação da população na definição de prioridades e na gestão dos recursos, através de Conselhos Locais e Municipais de Saúde;

$\mathrm{Na}$ área de habitação, destaca-se a inclusão da população como um novo ator, em que a questão dos recursos financeiros é um dos aspectos cruciais. Assim, a participação dos próprios usuários no processo construtivo viabiliza a redução de custos. Mas o envolvimento da população garante mais do que isto - ela tende a ser considerada crucial também para o controle do uso dos recursos, evitando os desvios de recursos públicos que têm caracterizado a área de habitação popular no país, através da articulação de interesses entre segmentos do setor público e empreiteiras e fornecedores de materiais. No Mutirão em Autogestão, programa habitacional da prefeitura de Ipatinga, Minas Gerais - uma ONG é a gestora dos recursos e do próprio programa habitacional. 
Outro caso em que um segmento da população diretamente atingido pela política pública é um dos atores a integrar o programa desenvolvido pelo setor público ocorre na área de segurança e saúde do trabalho. No programa Intervenção Ética de Impacto e Controle Social nos Ambientes de Trabalho, da prefeitura de Volta Redonda, no Rio de Janeiro - a formulação e a implementação da política - voltada à eliminação de riscos e problemas de saúde do trabalhador - se dá com a participação de sindicato dos trabalhadores.

Há exemplos também na área da cultura, como no programa Circo da Cidade, desenvolvido pelo município de Lages, em Santa Catarina, o qual consiste na criação de um centro cultural itinerante, montado em um circo, o qual se desloca entre os bairros da cidade, com o objetivo de possibilitar o acesso da população da periferia da cidade a atividades culturais e a participação na produção cultural. Em cada bairro, participam da definição da programação e do desenvolvimento das atividades associações de moradores, comissões de saúde, grupos de mães, de terceira idade e grupos de jovens.

$\mathrm{Na}$ área de abastecimento, uma experiência pioneira foi implantada em Campinas, no Estado de São Paulo - a CEASA de Campinas é responsável pela política de abastecimento do município sem contar com recursos públicos. Isto foi possível através do estabelecimento de parcerias com entidades do setor privado, pequenos produtores, entidades do Terceiro Setor que atuam na área assistencial, com instituto de pesquisa da área de alimentos e com outras instituições do próprio município, o que viabilizou também a criação de subprogramas que têm como foco específico a população de baixa renda.

Finalmente, ocorre envolvimento da população em programas voltados à modernização da gestão, como no caso do Democracia Caipira, de Campina de Monte Alegre, município do Estado de São Paulo, programa que consiste na implantação de um modelo de gestão pública em que os recursos são geridos com a participação de conselhos populares e em que, ao mesmo tempo, $100 \%$ dos serviços da prefeitura são terceirizados. Este é um caso particularmente interessante por integrar num só programa, conselhos populares, envolvidos na gestão de recursos, e a terceirização da totalidade dos serviços públicos da prefeitura, propondo um modelo de gestão sem funcionários públicos. O programa integra, assim, iniciativa habitualmente vinculada a propostas de democratização do processo decisório e de controle e gestão dos serviços públicos, a iniciativa que é consistente com a versão neoliberal de reforma, em que todos os serviços são privatizados ou terceirizados. Duas observações devem ser feitas a partir deste exemplo. Em primeiro lugar, a terceirização constitui tendência ainda embrionária no que diz respeito à prestação 
de serviços de educação e saúde. De outro lado, é importante registrar que propostas e programas de terceirização e de privatização não têm sido defendidas apenas por adeptos da perspectiva mais radical de redução do Estado, mas têm sido debatidas e propostas também por defensores do fortalecimento do Estado (e da reforma de sua ação) como via de garantir maior eqüidade social.

\section{CONCLUSÃO}

A inclusão de novos atores - da sociedade civil e do setor privado - na formulação, implementação e controle das políticas sociais no nível local - assinala uma inflexão importante com relação ao padrão de ação do Estado no campo social no país. De um lado, está havendo uma ruptura com o padrão não democrático de articulação entre Estado e Sociedade, caracterizado pelo clientelismo, pelo corporativismo e pelo insulamento burocrático. Caminha-se, ainda que de forma embrionária, para a ampliação do domínio público, o que inclui a publicização do próprio Estado, com a incorporação do universalismo de procedimentos à lógica das agências estatais (NUNES, 1997) ${ }^{11}$. Tal processo abre caminho para que a sociedade passe a cobrar os resultados da ação estatal, reduzindo - ao menos potencialmente - o déficit de accountability que tem caracterizado as políticas públicas no Brasil.

Mas a redefinição da esfera pública inclui também a construção de novos arranjos institucionais, que superam o modelo de provisão estatal e o padrão uni-organizacional centralizado que caracterizava o período anterior. Tais arranjos apontam para a construção de redes institucionais, que reúnem diversos atores, envolvendo articulações intersetoriais, intergovernamentais e articulações entre Estado, mercado e sociedade civil ${ }^{12}$. Tais redes são constituídas tanto para a formulação de programas como para a provisão dos serviços públicos, sugerindo que, na dinâmica recente dos governos locais do Brasil, as políticas sociais já escapam ao modelo tradicional de políticas sociais como atribuição exclusiva do Estado $^{13}$.

\footnotetext{
${ }^{11} \mathrm{O}$ universalismo de procedimentos constitui a base de normas e instituições que regulam o domínio público, definindo normas que valem para todos (independente de vínculos pessoais) e que pautam a relação entre Estados e cidadãos. CF. NUNES, 1997.

${ }^{12}$ SPINK se refere à constituição de um arranjo para-governamental de médio alcance de associações e ações organizacionais e sociais. (SPINK, 1997).

${ }_{13}$ Ao fazer tal leitura dos processos em curso não se pretende afirmar tratar-se de um processo homogêneo e consolidado, imune a retrocessos e ao convívio com práticas tradicionais. Como afirma NUNES, a introdução de novas instituições e gramáticas de relacionamento Estado e Sociedade no Brasil não tem significado a eliminação das precedentes, havendo combinações entre o antigo e o novo que não devem ser negligenciadas (NUNES, 1997).
} 
Ao afirmar que as políticas sociais no nível local já não parecem se restringir ao padrão de provisão estatal exclusiva procura-se chamar a atenção para a consolidação no nível local da capacidade de implementar políticas e de promover ações orientadas de alcance coletivo. Esta nova governança - em construção - supõe mecanismos de interlocução com diversos atores e a consolidação de parcerias. Como afirma DINIZ (1996):

"As novas condições internacionais e a complexidade crescente da ordem social pressupõem um Estado dotado de maior flexibilidade, capaz de descentralizar funções, transferir responsabilidades e alargar, ao invés de restringir, o universo dos atores participantes, sem abrir mão dos instrumentos de controle e supervisão..."”*

Os governos locais assumem assim um papel de coordenação e de liderança, mobilizando atores governamentais e não-governamentais e procurando estabelecer um processo de "concertação" de diversos interesses e de diferentes recursos em torno de objetivos comuns. Através dos novos arranjos institucionais assim constituídos tende a crescer a perspectiva de sustentabilidade de políticas públicas que, de outra forma, poderiam sofrer solução de continuidade a cada mudança de governo. O enraizamento das políticas em um espaço público que transcende a esfera estatal reforça a possibilidade de políticas de longo prazo $^{14}$, com repercussões sobre a eficiência e a efetividade das políticas implantadas.

\footnotetext{
${ }^{*}$ Grifo nosso

${ }^{14}$ Estudo de SPINK, CLEMENTE E KEPPKE (1998) revela que 88\% dentre 488 programas municipais inscritos em programa de premiação de iniciativas inovadoras em 1996 (Gestão Pública e Cidadania), "sobreviveram” à mudança de governo municipal em 1997. Dos programas que tiveram continuidade, $78 \%$ envolviam parcerias seja com agências governamentais seja com entidades da sociedade civil e do setor privado. Dos que foram interrompidos, $65 \%$ não possuíam formas significativas de parceria.
} 


\section{BIBLIOGRAFIA}

ARRETCHE, Marta Teresa da Silva. O processo de descentralização das políticas sociais no Brasil e seus determinantes. Tese de doutorado apresentada ao Departamento de Ciência Política do Instituto de Filosofia e Ciências Humanas da UNICAMP. 1998.

ARRETCHE, Marta. Concepções alternativas ao neoliberalismo: a proposta da CEPAL. ENCONTRO ANUAL DA ANPOCS, 17. 1993. (Texto digitado).

CÂMARA DO GRANDE ABC. Documento apresentado ao programa Gestão Pública e Cidadania. 1998.

CARDOSO, Fernando Henrique. Autoritarismo e democratização. Rio de Janeiro, Paz e Terra, 1975.

CRUZ, Maria do Carmo Meirelles Toledo. O consórcio intermunicipal de saúde da microregião de Penápolis como instrumento de viabilização dos sistemas locais de saúde. Dissertação de mestrado em Administração Pública. EAESP-FGV, 1992.

DINIZ, Eli. Em busca de um novo paradigma: a reforma do Estado no Brasil dos anos 90. São Paulo em Perspectiva, v.10, n. 4, p. 13-26, out.-dez. 1996.

DINIZ, Eli., Crise, reforma do Estado e governabilidade. Rio de Janeiro, Editora Fundação Getulio Vargas, 1999.

DOWBOR, Ladislau. Governabilidade e descentralização. Revista do Serviço Público, v.118, pp. 95-118, jan/jul. 1994.

DRAIBE, Sonia. As políticas sociais e o neoliberalismo. Revista USP, n. 17, p.86-101, mar/abr/mai. 1993.

DRAIBE, Sonia. Brasil: o sistema de proteção social e suas transformações recentes. Nepp, UNICAMP/CEPAL, Projeto Reformas de políticas para aumentar a efetividade do Estado na América Latina, 1992. (Texto datilografado).

EVANS, Peter. O Estado como problema e solução. Lua Nova, n. 28-29, p. 107-157, 1993.

FARAH, Marta Ferreira Santos. Parcerias, novos arranjos institucionais e políticas públicas locais. FUNDAÇÃO PREFEITO FARIA LIMA - CEPAM. O município no século XXI: cenários e perspectivas. São Paulo, 1999. Edição comemorativa dos 30 anos do CEPAM. 
FARAH, Marta Ferreira Santos. Reforma de políticas sociais no Brasil: experiências recentes de governos subnacionais. RAUSP - Revista de Administração, v.33, n.1, março1998 (a).

FARAH, Marta Ferreira Santos. Governo local, políticas públicas e novas formas de gestão pública no Brasil. O\&S - Organizações e Sociedade, n.17, 2000 (no prelo).

FRANCO, Rolando. La agenda social de América Latina: equidad y superación de la pobreza. (Trabalho apresentado à VI CONFERENCIA ANUAL DE LA RED SOCIAL DE AMÉRICA LATINA Y DEL CARIBE. La Trinidad, Tlaxcala, México, 8 a 10 de nov. de 1999)

IGLESIAS, Enrique. Repensar a politica para reinventar o Estado. Trabalho apresentado ao II FÓRUM GLOBAL SOBRE REINVENÇÃO DO ESTADO. Brasília, 29 de maio a $1^{\circ}$ de junho de 2000. http://www.21stcentury.gov.br

KLIBSBERG, Bernardo. Uma gerência pública para os novos tempos. Revista do Serviço Público, v.118, pp.119-142, jan/jul. 1994.

KLIKSBERG, Bernardo. ¿COMO REFORMAR EL ESTADO PARA ENFRENTAR LOS DESAFIOS SOCIALES DEL 2000? Trabalho Trabalho apresentado ao II FÓRUM GLOBAL SOBRE REINVENÇÃO DO ESTADO. Brasília, 29 de maio a $1^{\circ}$ de junho de 2000. http://www.21stcentury.gov.br

LIPIETZ, Alain. Audácia: uma alternativa para o século 21. São Paulo, Nobel, 1991.

MELAMED, Clarice. A experiência do médico de família em Londrina. In: SPINK, Peter e CLEMENTE, Roberta. 20 experiências de gestão pública e cidadania. Rio de Janeiro, Editora Fundação Getulio Vargas, 1997.

NUNES, Edson. A gramática política do Brasil: clientelismo e insulamento burocrático. Rio de Janeiro/Brasília, Jorge Zahar Editor/ENAP, 1997.

O'DONNELL, Guillermo. Reflexões comparativas sobre políticas públicas e consolidação democrática. In: MOURA, Alexandrina Sobreira. O Estado e as políticas públicas na transição democrática. São Paulo, Vértice, Fundação Joaquim Nabuco, Recife, 1989. pp. 390391.

PINHO, José Antonio Gomes, SANTANA, Mercejane Wanderley e CERQUEIRA, Margarida Bandeira. Gestão pública em busca da cidadania: experiências de inovação em Salvador. São Paulo, Programa Gestão Pública e Cidadania, 1999. (Cadernos Gestão Pública e Cidadania, v. 5) 
PORTELLA FILHO, Petrônio. O ajustamento na América Latina: crítica ao modelo de Washington. Lua Nova, 32, p. 101-131, 1994.

REZENDE, Flavio da Cunha. Os Leviatãs estão fora de lugar. Dados, v. 39, n.2, v. 39, n.2, p.195-210,1996.

SANTOS, Wanderley Guilherme dos. Cidadania e justiça. Campus, Rio de Janeiro,1979.

SPINK, Peter, CLEMENTE, Roberta e KEPPKE, Rosane. Governo local no Brasil: velhos mitos e novos processos. Paper apresentado ao Seminário Internacional Reestruturação e Reforma do Estado: Brasil e América Latina no Processo de Globalização. FEA-USP, 18-21 maio 1998.

SPINK, Peter. Paths to solidarity: somoe comments on "identification with the human species. Human Relations, 50, 8, p.1005-1014. 1997.

STIGLITZ, Joseph. O pós-Consenso de Washington. Folha de S. Paulo, Caderno Mais. p. 45, Domingo, 12 de julho de 1998. (Trechos selecionados de conferência pronunciada pelo vice-presidente do Banco Mundial, em janeiro de 1998, em Helsinque, intitulada "Mais instrumentos e objetivos mais amplos: rumos ao pós-consenso de Washington”)

TENÓRIO, Fernando Guilherme e ROZEMBERG, Jacob Eduardo. Gestão pública e cidadania: metodologias participativas em ação. RAP, v. 31, n. 4, p. 101-125, julho/agosto, 1997.

TENÓRIO, Fernando Guilherme e STORINO, Gylcilene Ribeiro. A sociedade é protagonistia na relação com o Estado? São Paulo, Programa Gestão Pública e Cidadania, 1999. (Cadernos Gestão Pública e Cidadania, v. 15) 